\title{
The Conception of the Archaeological Park in El-Zuma
}

\author{
Jolanta Juchniewicz
}

\section{Burial Mounds of El-Zuma on the UnEsco World Heritage List}

On the strength of decision 27 сом 8C.31, taken by the Un Esco World Heritage Committee in 2003, "Gebel Barkal and the Sites of the Napatan Region" became the first cultural heritage property in Sudan to be inscribed on the World Heritage List (C i, ii, iii, iv, vi / 2003; World Heritage Committee 2003, 115). The five archaeological sites which make up this property (Jebel Barkal, El-Kurru, Nuri, Sanam and El-Zuma) represent the Napatan and Meroitic cultures of the second Kingdom of Kush. The cemetery at El-Zuma has been recognized as representing unique burial traditions and a masterpiece of human creative genius. The Early Meroitic period saw the start of a series of cultural changes in inhumation practices in Nubia (Mahmoud El-Tayeb 2012).

The five sites together cover a stretch of land over $6 \mathrm{o} \mathrm{km}$ long. Gebel Barkal and the Sites of the Napatan Region, Sudan, were inscribed on the World Heritage List on the basis of cultural criteria (i), (ii), (iii), (iv) and (vi):

Criteria (i), (ii), (iii), (iv): The nominated pyramids and tombs, being also part of the special desert border landscape on the banks of the Nile, are unique in their typology and technique. The remains are the testimony to an ancient important culture that existed and flourished in this region only;

Criterion i: The rock-cut burials and temples, together with the pyramids and funerary chapels represent a masterpiece of human creative genius.

Criterion ii: The Amun temple at Gabel Barkal is a main center of once an almost universal religion and together with the other sites represents the revival of Egyptian religious values.

Criterion iii: Gebel Barkal and the other sites bear an exceptional testimony of the Napatan, Meroitic and Kushite civilizations that existed along the Nile between 900 BC and $600 \mathrm{AD}$.

Criterion iv: The tombs, pyramids and temples are special and outstanding examples of architectural ensembles (ICOMOS 2003, 101).
1.1 Authenticity and Integrity: Challenges Regarding the Property's Protection and Conservation

\author{
Authenticity
}

Properties nominated under criteria (i) to (vi) must meet the conditions of authenticity.

World Heritage Committee 2017, para. 79

Integrity

All properties nominated for inscription on the World Heritage List shall satisfy the conditions of integrity.

World Heritage Committee 2017, para. 87

The fundamental premise of protecting monuments, in particular those inscribed on the UNESCO list of World Heritage sites, is that their historic substance should be fully respected. The high degree of intactness of these sites' attributes means that they require adequate preservation measures executed to modern scientific standards. Protection and conservation are major challenges because they have a significant impact on the authenticity and integrity of a property. It is necessary to preserve and permanently protect monuments without violating their original structure. All reinforcements, according to the current standards, should be hidden in order not to disturb the impression of authenticity (Małachowicz 2007, 235).

The Venice Charter of 1964 is the International Charter for the Conservation and Restoration of Monuments and Sites, which sets out international standards of protection practice for architecture and sites. It defines the principles of protection based on the concept of authenticity and provides an international framework for the conservation and restoration of historic buildings.

Excerpts from the Venice Charter (ICOMOS 1964):

\section{Restoration}

Article 9. The process of restoration is a highly specialized operation. Its aim is to preserve and reveal the aesthetic and historic value of the monument and is based on respect for original material and 
authentic documents. It must stop at the point where conjecture begins, and in this case moreover any extra work which is indispensable must be distinct from the architectural composition and must bear a contemporary stamp. The restoration in any case must be preceded and followed by an archaeological and historical study of the monument.

Article 10. Where traditional techniques prove inadequate, the consolidation of a monument can be achieved by the use of any modern technique for conservation and construction, the efficacy of which has been shown by scientific data and proved by experience.

Article 12. Replacements of missing parts must integrate harmoniously with the whole, but at the same time must be distinguishable from the original so that restoration does not falsify the artistic or historic evidence.

Article 13. Additions cannot be allowed except in so far as they do not detract from the interesting parts of the building, its traditional setting, the balance of its composition and its relation with its surroundings.

When working on monuments, certain rules should be followed in accordance with modern conservation principles:

1. the PRIMUM NON NOCERE principle,

2. the principle of maximum respect for the original fabric of a monument and all of its values (material and intangible),

3. the principle of minimum necessary interference (refraining from unnecessary works),

4. the principle of removing only those elements that destructively influence the original,

5. the principle of discernibility and distinguishability of complements and current interferences and their aesthetic subordination to the original (the principle of non-competition),

6. the principle of reversibility of methods and materials,

7. the principle of performing all works in accordance with best knowledge and safeguarding top quality, including full documentation of research results and the course of subsequent works (Narodowy Instytut Dziedzictwa, n.d.).

\subsection{The Concept of Cemetery Protection in El-Zuma}

The unesco Management Plan for the sites of the Napatan Region, drawn up in 2003, includes some guidelines on how to protect monuments. Among other things, there should be protection against degradation caused by natural factors and human activity (Ahmed 2003, 251252 ).

The ancient cemetery in El-Zuma is liable to degradation due to the combination of natural hazards and human activity. The monuments at this site have never been professionally conserved and need long-term protection. The following is a preliminary analysis of how to stop or reduce the impact of these factors by finding optimal methods of care and conservation.

In order to adequately protect the archaeological heritage in El-Zuma in accordance with UNESCo's principles of local community participation, the idea of an archaeological park has been put forward. Opening the site to tourists will strengthen the local economy and, hopefully, foster better stewardship of the monuments among the local population.

The concept of comprehensive protection of the graves at the cemetery in El-Zuma encompasses several elements: reinforcement and protection of aboveground features (tumulus superstructures), strengthening of underground features (shafts, burial chambers, and tunnels), as well as protection against damage. The underground parts must be adapted for tourist purposes in such a way that they guarantee the safety of visitors while below ground.

The most urgent conservation action at the archaeological site in El-Zuma is the protection of those tombs that are open and have only temporary protection (T.2, T.5, T.12, and T.25). From year to year there is noticeable progressive erosion of the rock substrate into which the (currently open) burial shafts were hewn. Rainwater has direct access to the inside of the tombs, which leads to erosion of the shaft walls. Existing protective measures only safeguard the tumuli from destructive human activity and prevent any accidental falls into deep excavations [Fig. 9.1].

Protection against the destruction of shafts and tunnels should start with structural consolidation of their surfaces. The most suitable method for treating porous rock such as that encountered in El-Zuma is impregnation of the surface with a deep-penetrating agent that will not form sealing layers, so that moisture can evaporate freely.

A set of guidelines for the implementation of all rescue operations for underground and above-ground historic assets, devised by Zalewski and Strzelecki, focuses on geomechanical aspects such as:

- carrying out monitoring surveys of the site substrate;

- using laboratory tests to accurately identify the physical and mechanical properties of the ground (rock mass) in and around the historic monument;

- the role of non-destructive testing in determining the current stability of excavations; 


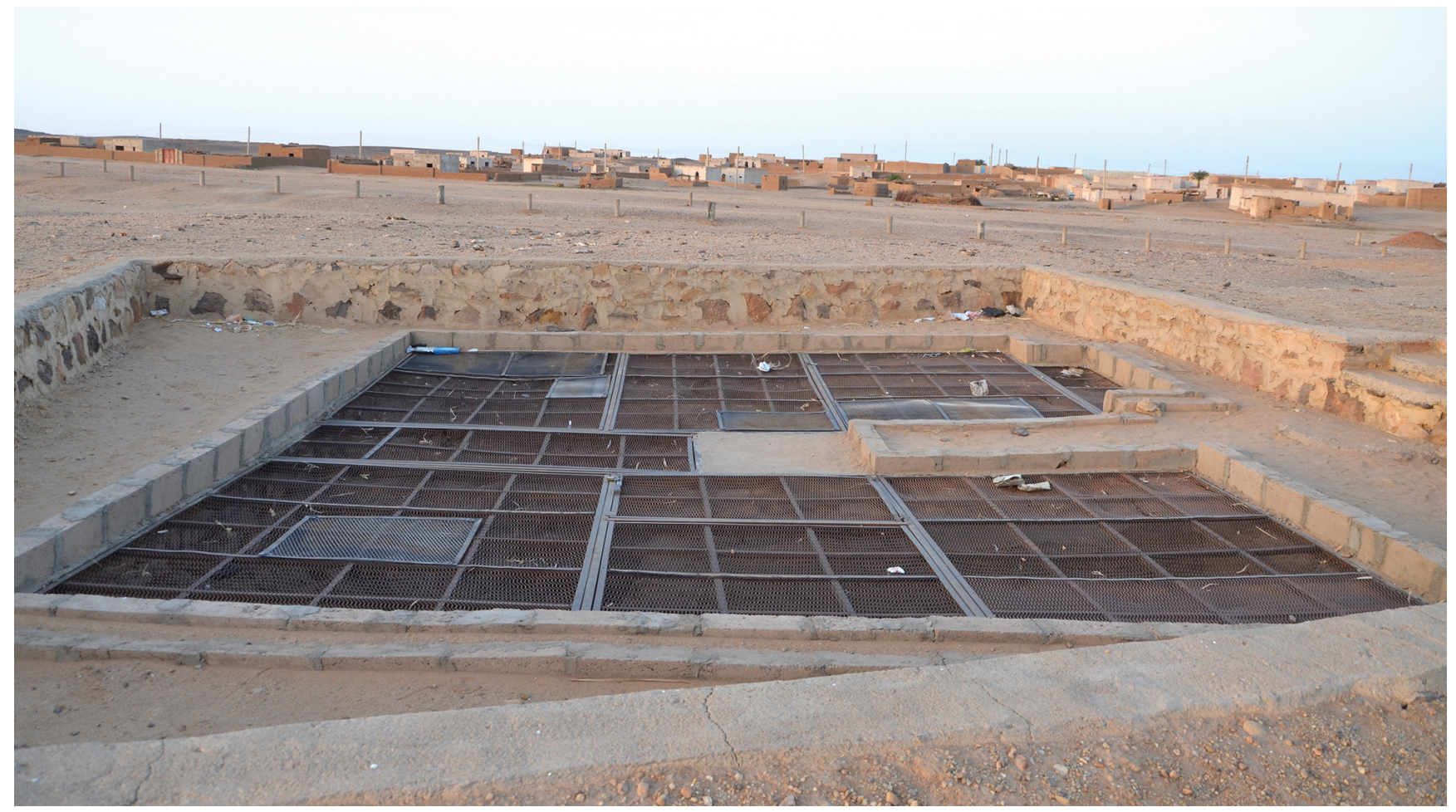

FIGURE 9.1 Tumulus 12: temporary protection PHOTO BY Z. KOWARSKA

- static strength analysis of individual technical solutions for ground stabilization and consolidation of underground heritage assets (Tajduś, Mikoś, and Chmura 2006, 306).

The method formulated by Zalewski and Strzelecki requires a specific, multidirectional plan of action, the implementation of which guarantees the elimination of the causes and effects of the addressed threat.

\subsubsection{Consolidation of Burial Shafts}

The substructures of the burial mounds are carved into weak, sedimentary bedrock. It consists mainly of sandstone with an adhesive clay that is very susceptible to weathering and is characterized by low compressive strength. Diverse geological factors make it very difficult to choose a method for protecting and consolidating the rock mass. To safeguard the excavated tombs, there is no doubt that some kind of shelter is necessary, providing a cover for the shafts to protect them from destructive atmospheric conditions. Such a construction should, moreover, provide very good ventilation to help remove the excess moisture generated by the rise in groundwater levels caused by the Merowe Dam.

Typical mining methods for safeguarding underground monuments cannot be used here. Any reinforcement in the form of visible elements of casings, struts, or sprayed concrete would disturb the impression of authenticity. Shaft walls, which reach a height of almost $6 \mathrm{~m}$ in the deepest tomb, should be protected in the least visible way and without compromising the tomb's historic fabric. In addition, the face of the rock is so weathered that cleaning of any contaminants cannot take place without a severe loss of material. The surface of the shaft should be impregnated, sealed, and consolidated with chemical agents. The next stage should focus on strengthening the shaft walls with special mining methods.

The surface of the rock in the tombs is porous, therefore the most suitable consolidation agent will be one with good penetration depth that does not form layers that seal the surface. One agent that meets the above requirements is the one-component KSE 510 from Remmers, containing organic solvents based on ethyl esters of silicic acid (Ks). ${ }^{1}$

The walls of the burial shafts should be protected against damage by special mining methods. In the case of eroded, weak, cracked, and damp walls, and given the requirement to avoid using visible reinforcements, it would be beneficial to use spiral ground anchors. Anchors of this type increase the internal strength of the rock mass while being almost invisible from the outside. However,

1 http://www.remmers.pl/3823.o.html, accessed 16 February 2015. 
anchoring weak or cracked rock involves the risk of the rock loosening between the anchor points. To ensure the effectiveness of this method, a steel mesh must also be used to stabilize the surface with the anchor. The advantage of using spiral ground anchors is that they can be easily dismantled if necessary. This anchoring system works regardless of atmospheric conditions, allows installation in places with limited access, is trenchless, and does not require holes to be drilled for the anchors. An additional advantage is immediate checking of the assumed strength parameters and load of the anchors. The choice of the size of anchors and their arrangement depends on the ground conditions and the loads involved. The mesh used to stabilize the shaft walls should be made of stainless steel to prevent the risk of corrosion. Its colour should be as close as possible to the colour of the rock to minimize its visibility.

\subsubsection{Strengthening of Tunnels}

The tunnels leading to the burial chambers beneath the tumuli are carved into the same weak rock as the shafts [Fig. 9.2]. The largest tunnels are up to $20 \mathrm{~m}$ long (T.6) with a problematic cross-section of approximately $4 \mathrm{~m}$ wide by approximately $1.5 \mathrm{~m}$ high in the case of tunnels with pillars in the middle. This poses a major challenge to ensuring the safety of the tunnels, necessitating the use of unusual structural solutions and preventive measures. In addition, long-term excavation has resulted in the development of multiple cracks in their surroundings. As it is not possible to use fully reliable reinforcement solutions in the form of mining enclosures, there are no plans to allow visitors into any of the tunnels. Maintenance works are designed to secure the existing structures for as long as possible without any visually intrusive interference. Just as in the case of the burial shafts, the preferred solution is the use of surface impregnation with organosilicon consolidants and strengthening of the rock mass with spiral ground anchors together with a steel mesh.

\subsubsection{Consolidation of Tumulus Superstructures}

The superstructures of the burials are conical-shaped mounds with a slope of up to $30^{\circ}(58 \%)$. Depending on the type of tumulus, it is made up of a mixture of soil and gravel or pure sand with gravel. Some of the type I tumuli are high mounds of up to $8.5 \mathrm{~m}$. Their durability is threatened by erosion and downslope flows triggered by heavy rain.

The shape and structure of the tumuli make them susceptible to slope failure. Loss of existing slope stability creates new forces or leads to a reduction of friction forces (Stryczek, Gonet, and Wiśniowski 2008, 78).
The phenomena that destabilize the tumulus slopes include:

- an increase in soil humidity caused by long-lasting or very intense precipitation, which causes swelling and thus reduction of frictional forces and soil cohesion; - vibrations caused by, for example, road traffic.

These factors cause the uncompacted material that makes up the tumuli to gradually slide down their slopes.

To protect the mounds and stop these destructive processes, tumuli should be consolidated and their surfaces stabilized. Vibrations produced by road traffic should also be eliminated. Methods for stabilizing slopes include the use of geotextiles, steel mesh, or anti-erosion mats. The chosen method should have a minimal impact on the appearance of the reinforced surface and provide drainage of the slopes.

The use of flexible slope surface stabilization systems in the form of steel wire mesh combined with nailing would give the possibility of merging and masking new reinforcements in the structure of the mounds.

\subsubsection{Tumulus Reconstruction}

The tombs at El-Zuma need to be strengthened and protected through conservation and restoration. This has prompted the idea of reconstructing several tumulus superstructures, both to protect the tombs and make them accessible to visitors.

According to UNEsco's Operational Guidelines in relation to authenticity, the reconstruction of archaeological remains is justifiable only in exceptional circumstances and acceptable only on the basis of documentation, without conjecture [Fig. 9.3].

The following concept of tumulus reconstruction meets several objectives: it faithfully reconstructs the shape of the original earth superstructure, ensures access to the inside of the tomb, and creates a protective cover for the historic fabric. These objectives will be achieved by building a dome over the excavated tumulus grave and then covering it with earth to reconstruct the burial mound. By placing a skylight at the top of the dome, interior lighting will be provided. The use of photovoltaic cells at the top of the mound (hidden in the new structure) or alongside information panels will enable the provision of electricity for the lighting of burial chambers and tunnels [Fig. 9.4].

The dome will consist of a lightweight durable frame, which will be fitted with a rigid membrane to ensure adequate ventilation. Covering the dome with earth will make this new feature blend into the landscape and reconstruct the tomb's earthen superstructure [Fig. 9.5]. The dome will be placed around the perimeter of the excavated tomb on a foundation of helical screw piles, which will 

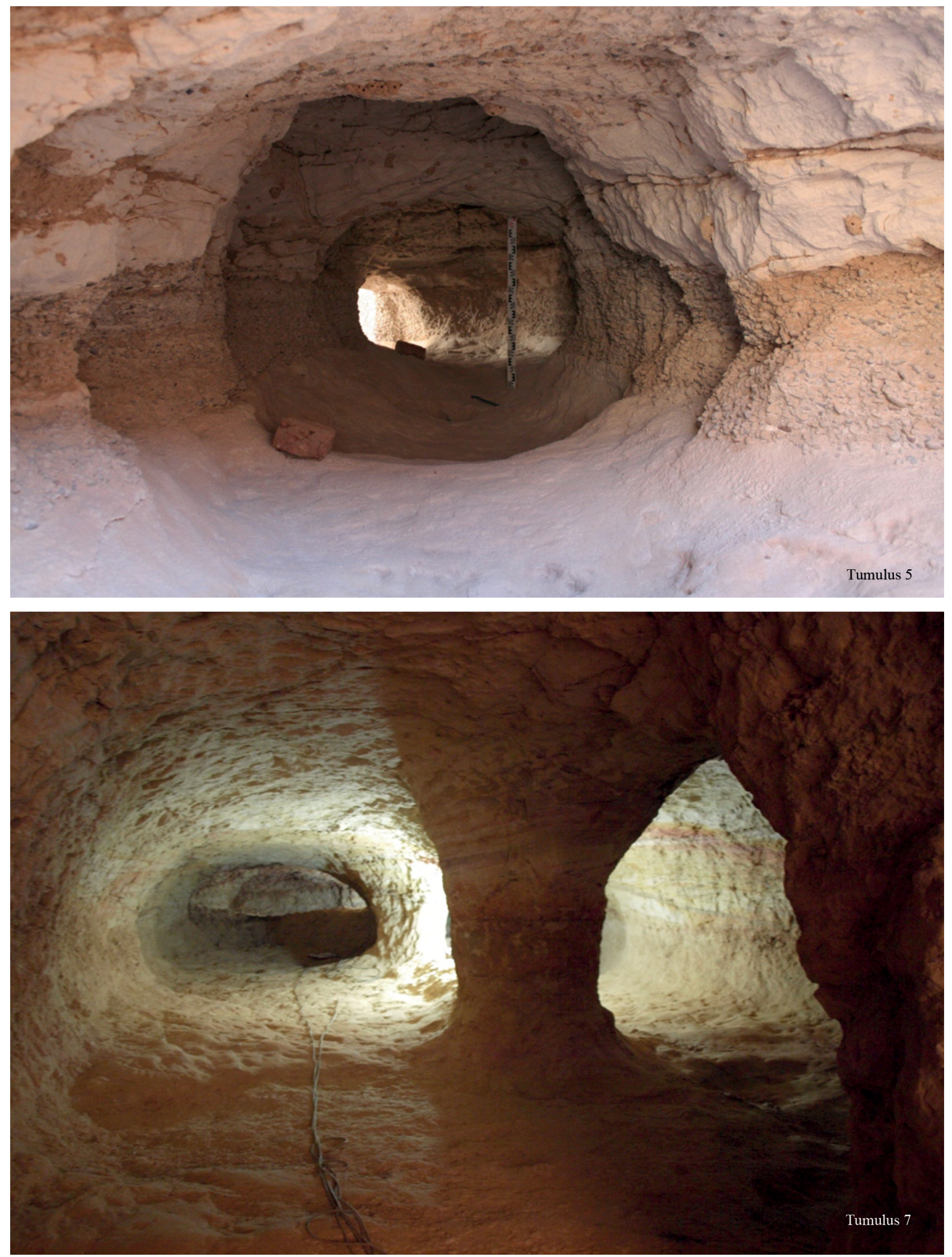

FIGURE 9.2 A view of the tunnel in tumulus 5 (top), and a view of the tunnel in tumulus 7 with pillars in the middle

PHOTOS BY K. JUCHNIEWICZ 


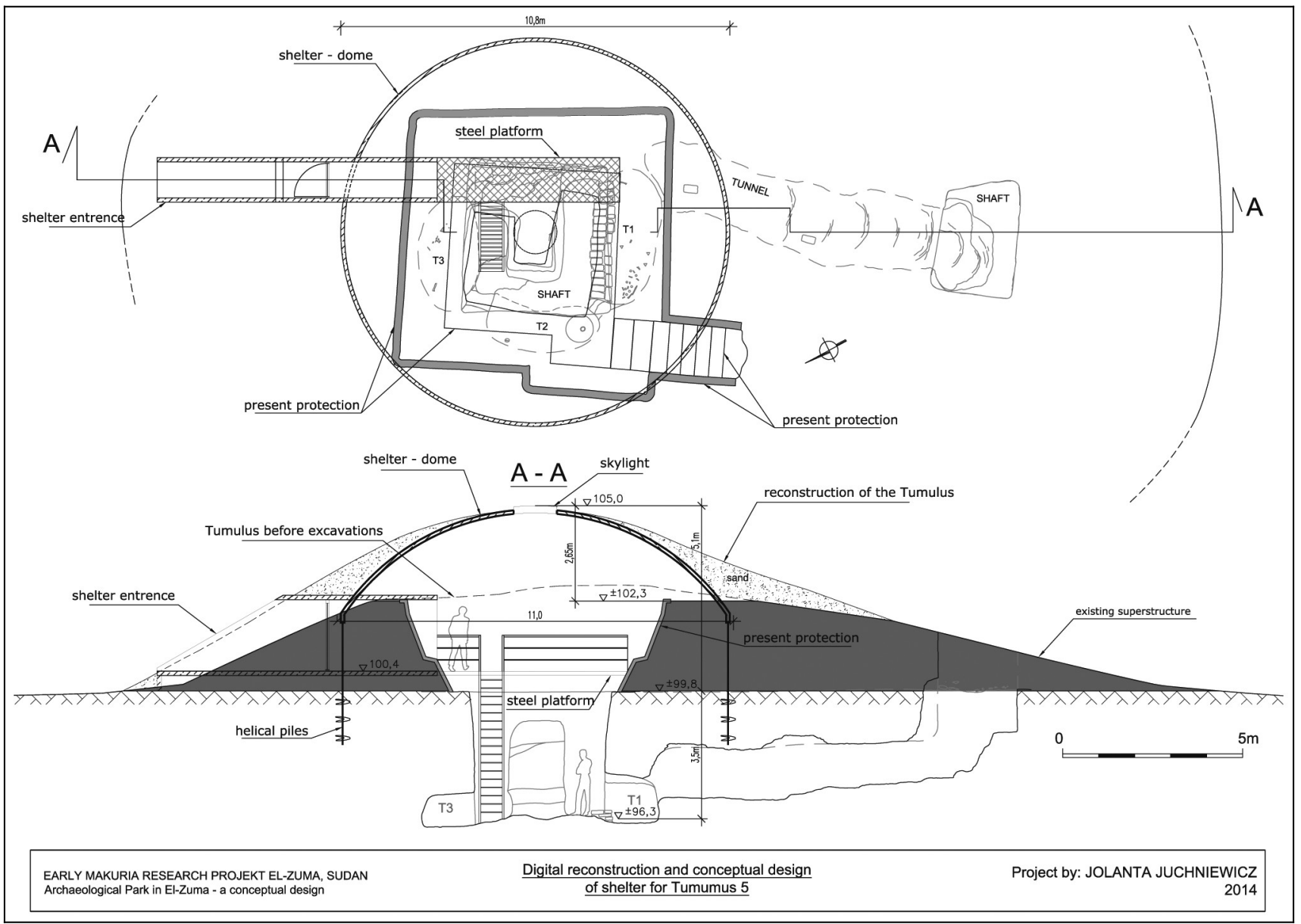

FIGURE 9.3 Proposed design for the reconstruction of the T.5 mound along with its protective structure PRODUCED BY J. JUCHNIEWICZ
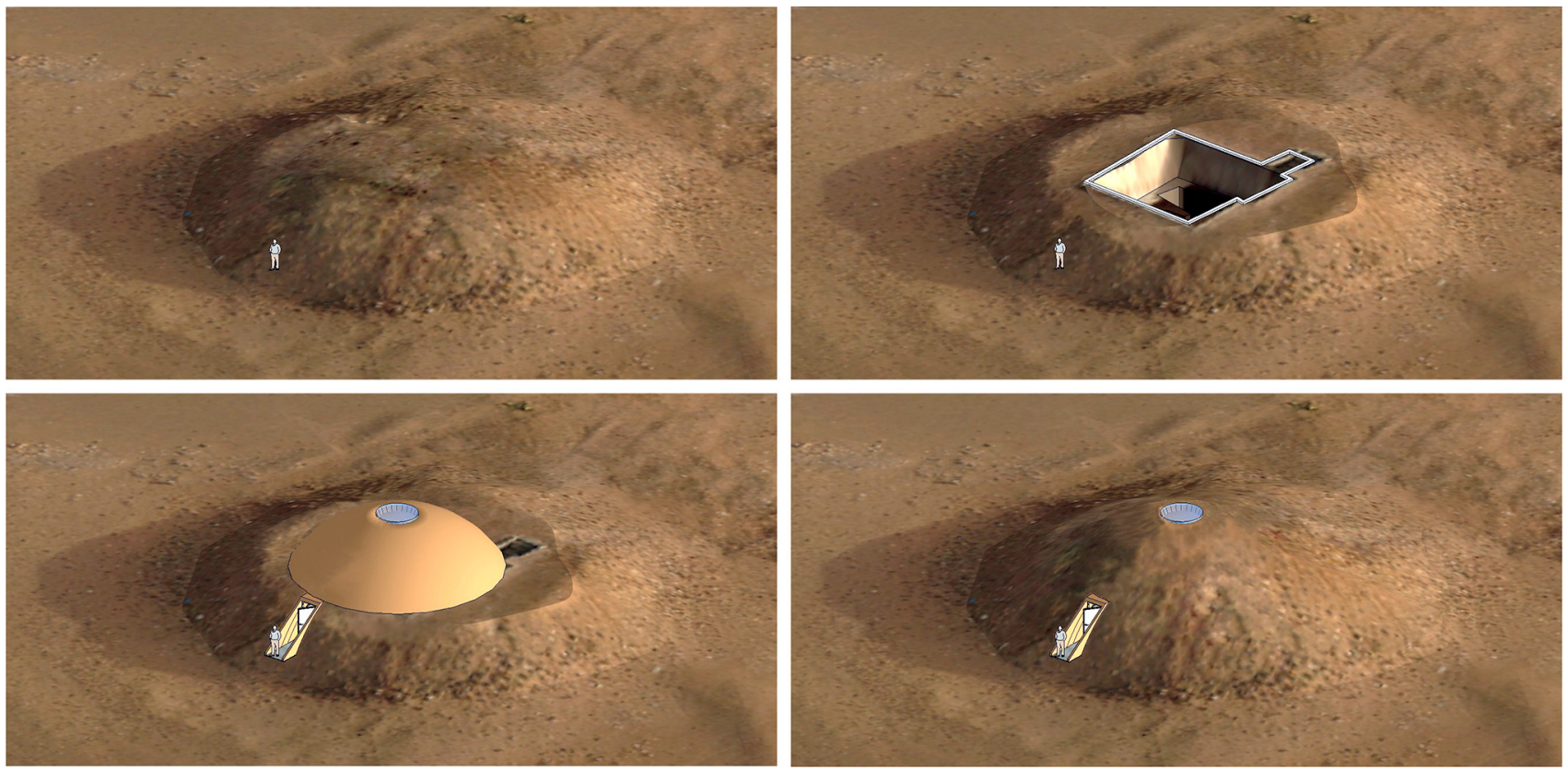

FIGURE 9.4 Computer reconstruction of tumulus 5: upper left—original state; upper right—state after excavation and installation of temporary safety measures; lower left-building the dome; lower right - the final reconstruction of the tumulus PRODUCED BY J. JUCHNIEWICZ 

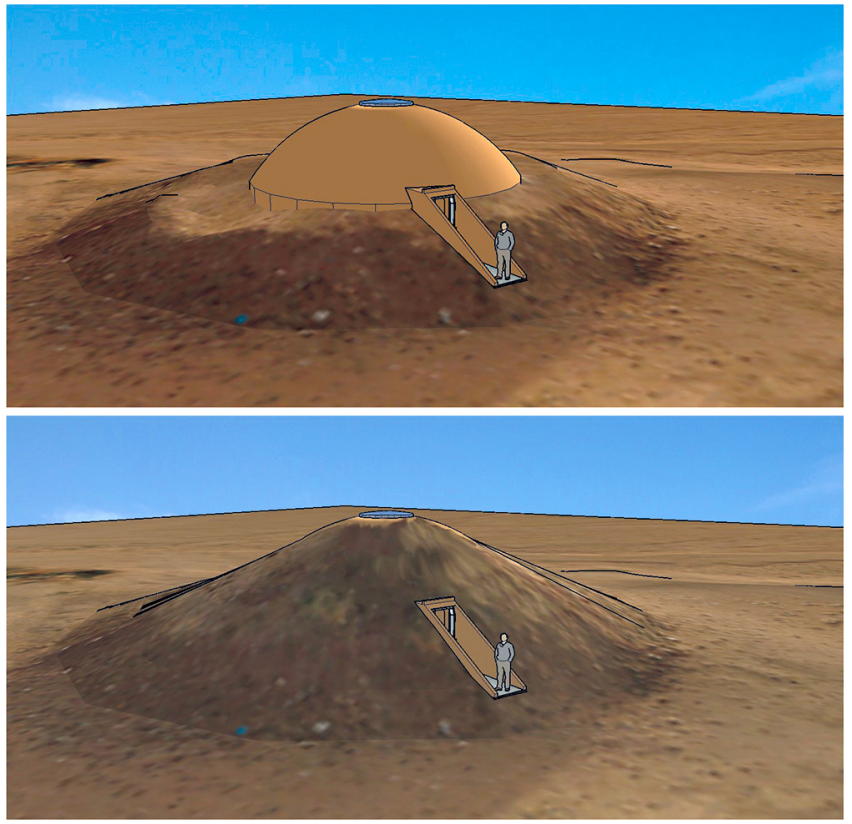

FIGURE 9.5

Tumulus 5: top — construction of the dome; bottom — final reconstruction of the tumulus

PRODUCED BY J. JUCHNIEWICZ
ROCK ANCHOR SYSTEM

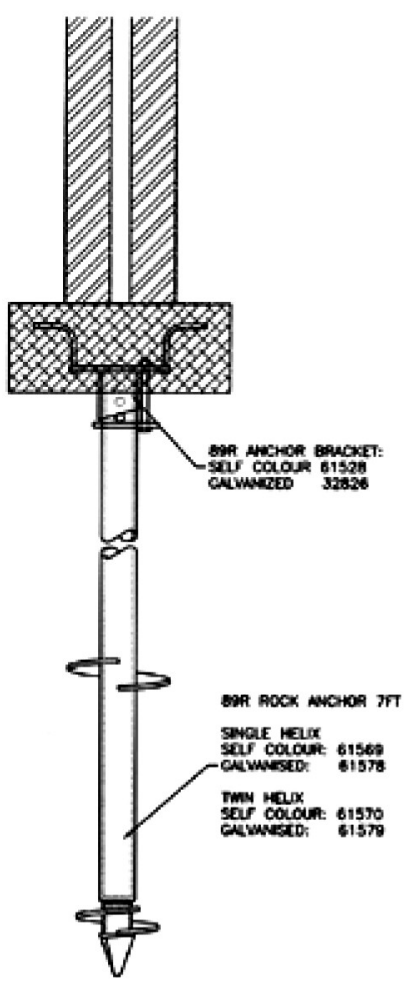

FIGURE 9.6

Drawing of a helical screw pile, ABC Anchors \& Autoguide Equipment product information WWW.ABCANCHORS.CO.UK

- can be easily load/proof tested if required;

- limited soil damage;

- suitable for any displaceable ground;

- bespoke designs available.

Modern composite profiles are suitable as structural components. They can be used as a substitute for steel, aluminium, and wood, wherever high-resistance parameters for corrosion, longevity, and durability, as well as low weight, are required. They are characterized by good physico-mechanical parameters, such as a high tensile strength of approximately $230 \mathrm{MPa}$, a very high compressive strength of approximately $950 \mathrm{MPa}$, and excellent flexibility (a bending strength of approximately 950 MPa), and hardness (approximately $400 \mathrm{~N} / \mathrm{mm}^{2}$ ).

Composite profiles are made of various types of resins. Reinforcement (approx. 70\%) is achieved by using glass, basalt, carbon fibres, or aramid fibres (Kevlar). Thanks to their unique structure, composite profiles have shape memory, which means that they can temporarily deform under the influence of an acting force, and then return to their original form without losing their parameters. The products can be given any colour at the production stage.
2 https://www.anchorsystems.co.uk/products/helical-anchors/, accessed 7 July 2019. 
When using glass or basalt fibre as the main raw material, constituting $70-80 \%$ of the composite, the products based on them are considered to be pro-ecological products, subject to easy and full recycling, without adverse impact on the natural environment and humans.

The advantages of composite profiles include:

- low weight (about $2.0 \mathrm{~g} / \mathrm{cm}^{3}$ ) - four times lighter than steel;

- high mechanical strength;

- any shape on request;

- resistance to low and high temperatures;

- resistance to changing weather and UV radiation;

- resistance to corrosion and chemical agents (no additional maintenance or protection required);

- long working time with minimum maintenance;

- low coefficient of thermal expansion;

- high impact resistance;

- flexibility and elasticity;

- can be dyed in bulk in any colour.

\section{$2 \quad$ Plans for the Archaeological Park in El-Zuma}

\subsection{The Main Concept of the Archaeological Park}

The creation of an archaeological park at the El-Zuma site is aimed at protecting the tombs and making them accessible to the public. All works should comply with the recommendations of UNESCO, be minimally invasive, and fully respect the site's historic substance and landscape.

The planned visitor route should be both interesting and informative, helping visitors to understand the site and its monuments while also ensuring a minimum of comfort for sightseeing. Tracks across the site will be designed with both guided tours as well as individual visitors in mind.

A suitable means is required for exhibiting the tomb interiors with their burial chambers and equipment. The protective structure covering each tomb should ensure visitor safety, provide good ventilation, and shield the archaeological remains from weather conditions such as rain and windblown sand. Protection of this sort should be given in the first instance to tombs with small earth mounds (T.2, T.5, T.12, T.25), which are currently open and secured only by a brick perimeter and a temporary mesh that does not protect the interior of the tombs from progressive erosion. These new constructions, which would provide the opportunity for tourists to go down into the burial shafts, would be equipped with convenient descents, barriers, and natural and artificial lighting. The shape of the new structures should be sympathetic to the landscape. A very important aspect is to minimize interference with the tombs' his- toric fabric. Also, it should be possible to dismantle the modern shelters without causing any damage to the original substance in case the shelters need to be replaced or should better methods of conservation and protection be developed in the future.

Two of the tombs selected for exhibition (T.2 and T.5) would need to have their earthen superstructures rebuilt. Currently, they each have only the flattened remains of a tumulus. Based on archaeological documentation, it would be possible to restore the original shape of the mounds. Research indicates that these tombs, both of which represent type I and have underground tunnels leading to the main burial chamber, were originally covered with a characteristic earthen superstructure.

An important goal of the archaeological park is to raise cultural awareness among the local community and to educate them about their cultural heritage, especially that recognized as having Outstanding Universal Value. The creation of the archaeological park would also generate jobs related to tourism: the production of souvenirs, traditional crafts, the organization of trips within the area of the archaeological park (on camels and in offroad vehicles), etc. Building a cultural centre with a local museum at the archaeological site will serve local inhabitants as well as tourists. The archaeological park will require basic infrastructure, including car-parking areas near the site.

An important element of the archaeological park's protection is its perimeter fence. The real problem is unauthorized urbanization without any consideration for the archaeological site and its environs. Moreover, vehicles travelling between the tumuli cause vibrations that may contribute to the destruction of the site's underground structures.

\subsubsection{Site Extent and Features}

The proposed archaeological park covers an area of approximately $207,000 \mathrm{~m}^{2}$ (21 hectares), and its perimeter is almost $2 \mathrm{~km}$ long. In keeping with UNESCO recommendations, in 2014 a complete map of the property was drawn up to clearly identify its boundaries. For the purposes of effective protection, a buffer zone was delineated around the site (World Heritage Committee 2017, para. 104). This zone stretches approximately $15 \mathrm{~m}$ from the border of the site along almost its entire perimeter. Within this zone any building activity is strictly prohibited. The boundaries of both the site and its buffer zone were topographically specified with the permission (and in the presence) of the local authorities.

The site boundaries are delineated by a semi-open fence system of 1-m-high reinforced concrete posts, spaced 


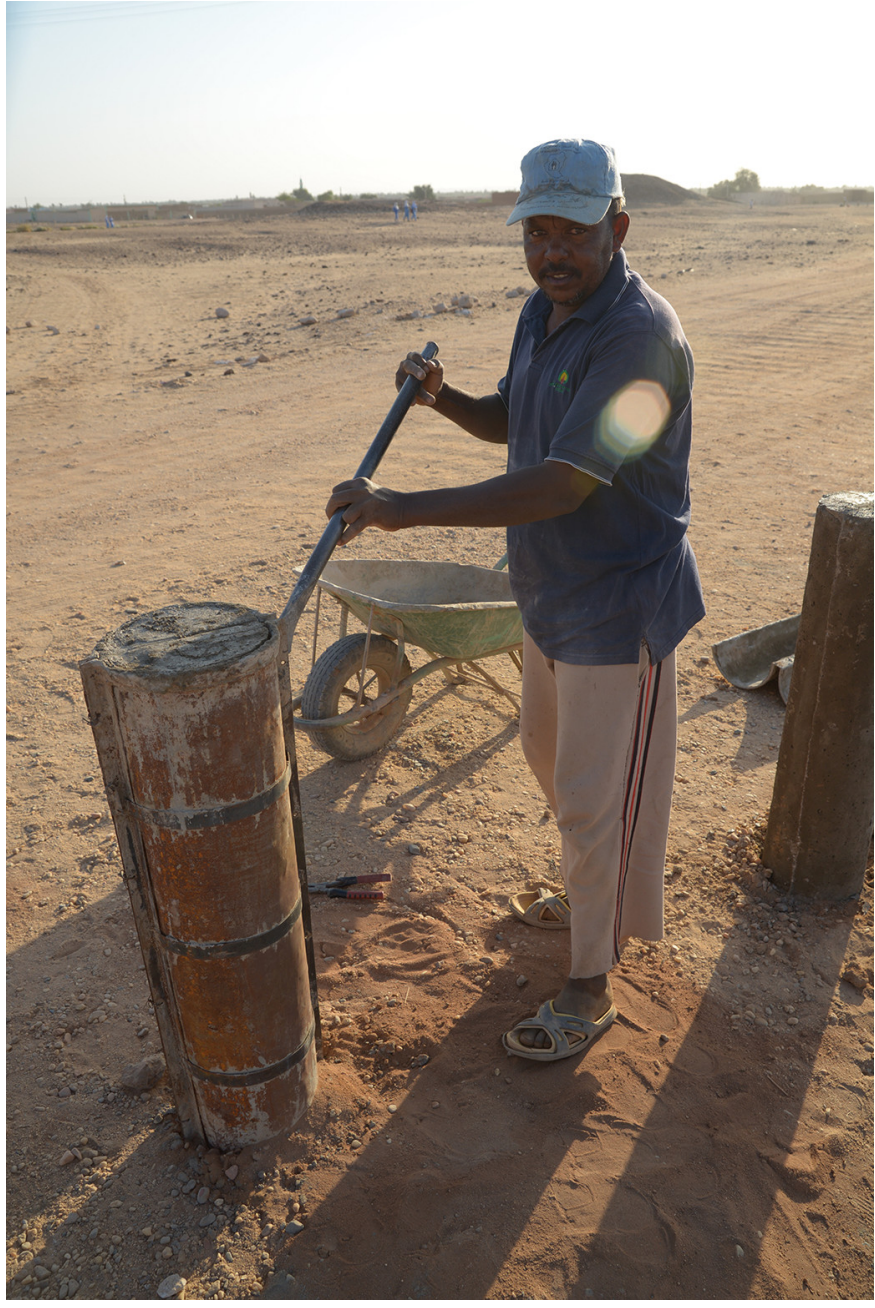

every $1.5 \mathrm{~m}$, which prevent vehicles entering the protected area. Such a system leaves the site open to visitors and accessible to local inhabitants. From a practical point of view, it is more durable and does not need maintenance in contrast to metal fences (plastic bags and other lightweight refuse do not become entangled in it) [Fig. 9.7].

In 2014 an old house located close to the eastern border of the site was reconstructed and designated as a headquarters for the tourist police, who safeguard monuments and provide security for tourists. One of the buildings is also a storeroom for artefacts recovered from excavation [Fig. 9.8].

\subsubsection{Access Road, Entrances and Car Parks}

The archaeological site is located $400 \mathrm{~m}$ from the main road to Khartoum, and the first burial mounds are clearly visible from it. The site is marked by a billboard [Fig. 9.9]. One of the two main entrances to the archaeological park, together with a large car park, is to be located as close as possible to the main road. Tourist-car traffic should arrive directly from the main road without entering the village.
FIGURE 9.7

Construction of the concrete posts PHOTO BY A. KAMROWSKI

The access road to the large car and coach park of the archaeological park would branch off from one of the two main dirt roads leading to the village of El-Zuma, marked by a dotted line on the map shown in Fig. 9.10.

This large car and coach park (number 1 ) is planned outside the area of the archaeological park. Due to the hard ground surface, the car park will not be paved. Its area will be demarcated by small concrete pillars.

Main entrance number 1, from the north-west side, will be equipped with a guard building and an information centre with a ticket office. There will also be a large information panel about the archaeological site and the history of El-Zuma's burial mounds. The archaeological park itself will be open to tourists; however, visiting the tomb interiors will only be possible with a guide.

Entrance number 2 is planned at the south-eastern end of the site, next to a museum and administration complex. Due to the very close proximity of other buildings and the lack of manoeuvring space, no coach entry is planned there. A small car park (number 2) will be located within the bounds of the archaeological park. 
A

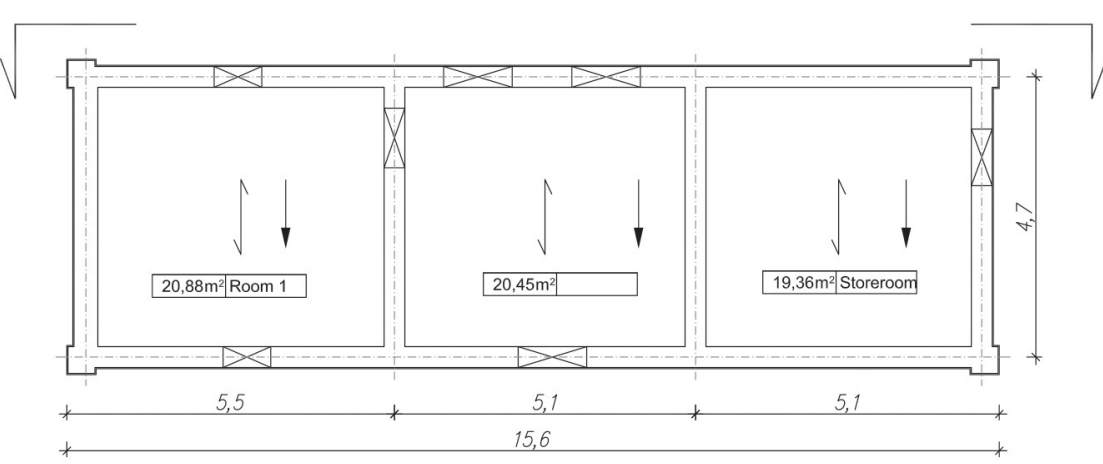

A - A

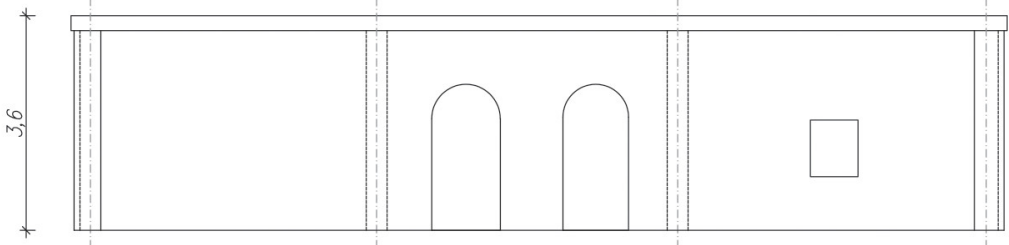

0,4

9.4

4,7

果事

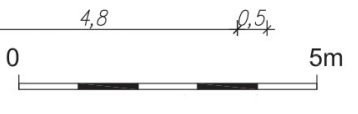

EARLY MAKURIA RESEARCH PROJECT EL-ZUMA, SUDAN Archaeological Park in El-Zuma - a conceptual design

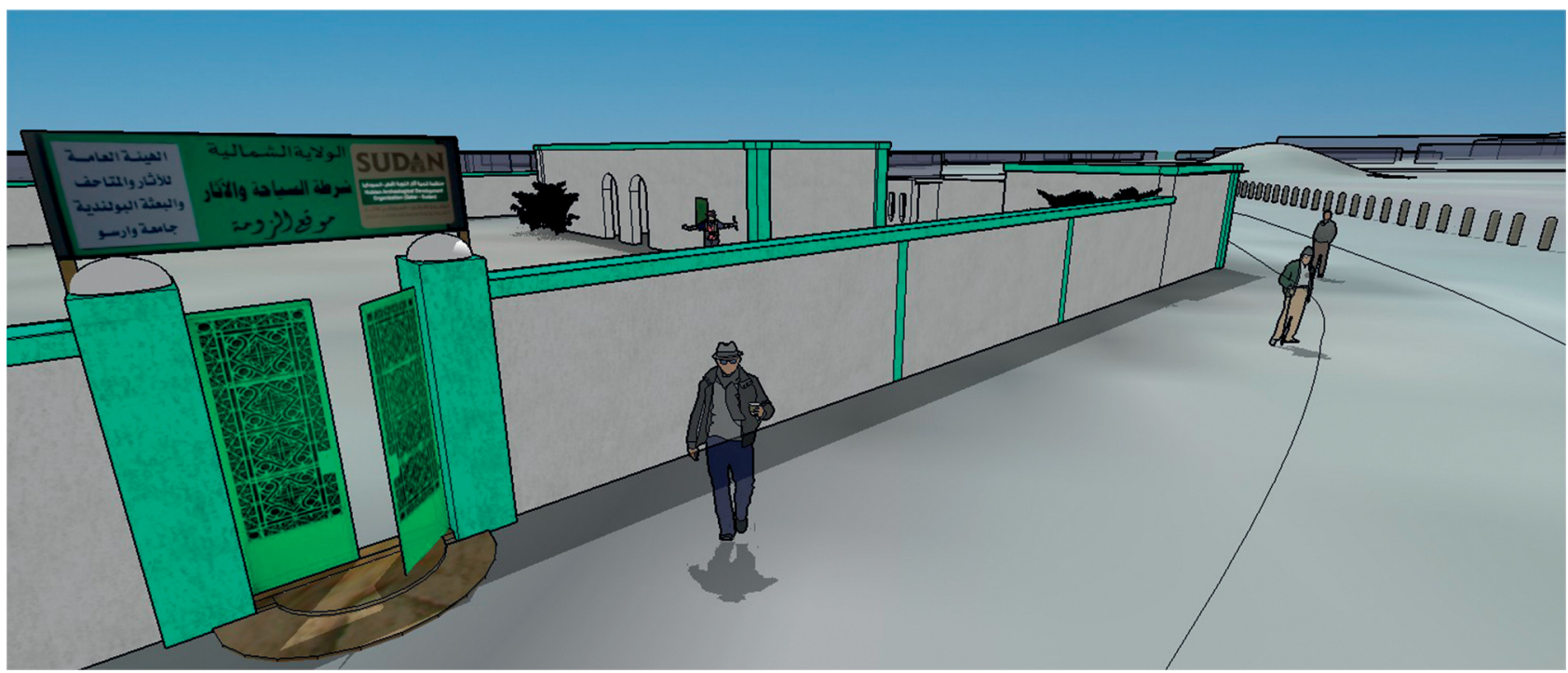

FIGURE 9.8 Plan of tourist police station (storeroom) and visualization of the tourist police station at the archaeological park

PRODUCED BY J. JUCHNIEWICZ 

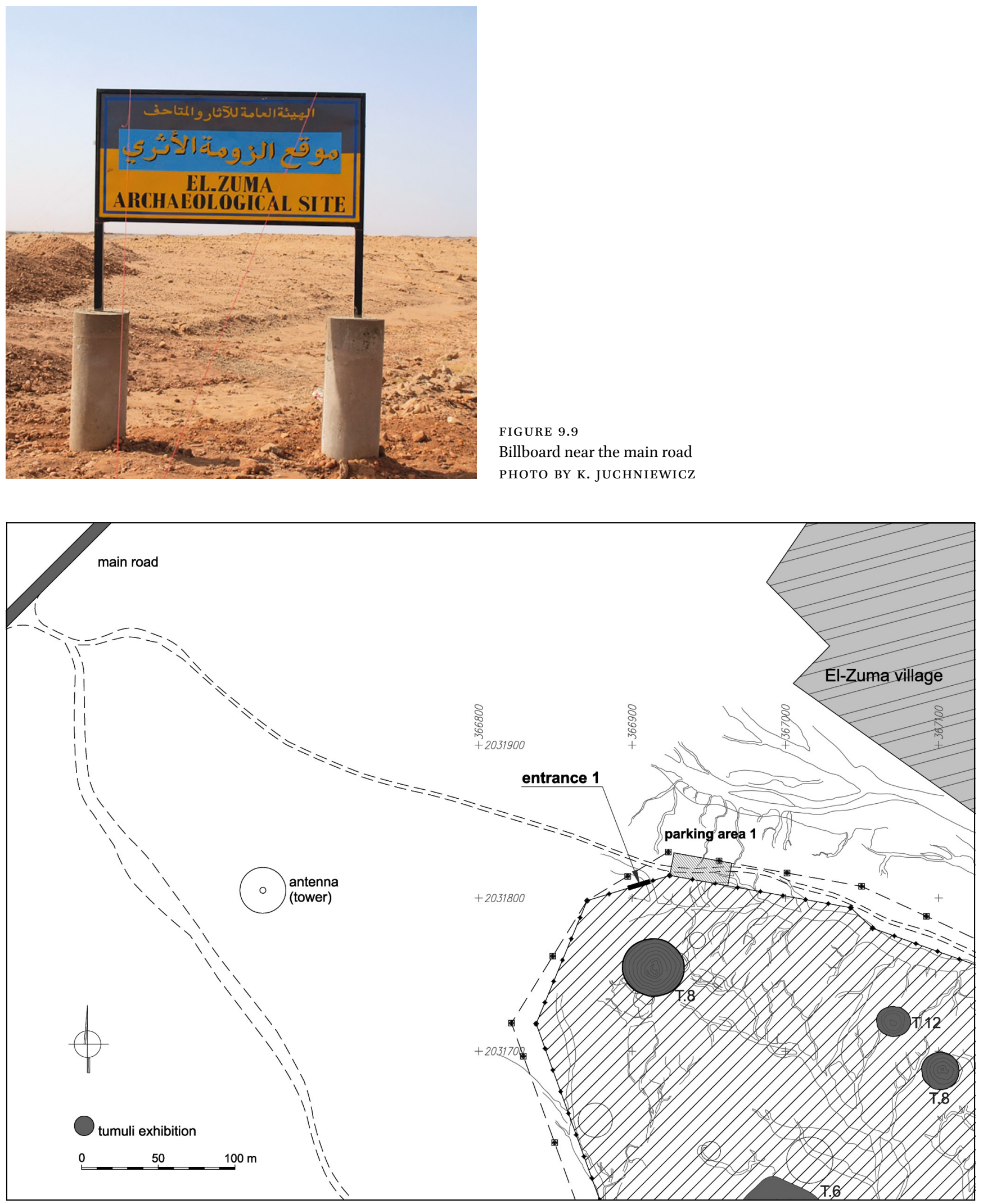

FIGURE 9.10 Map of the archaeological park, northern part PRODUCED BY J. JUCHNIEWICZ 


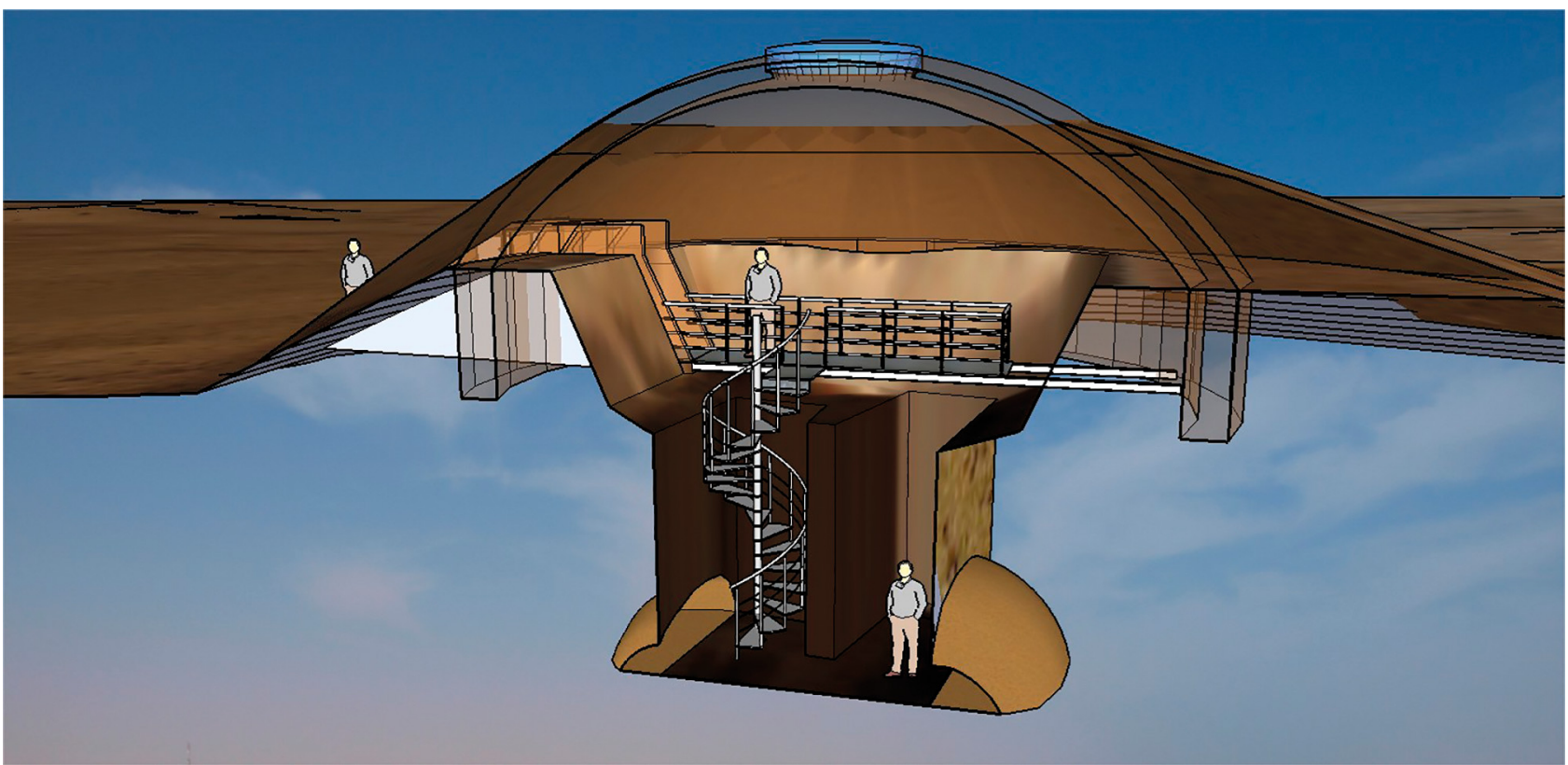

FIGURE 9.11 Cross-section through the structure of the dome and tumulus 5 PRODUCED BY J. JUCHNIEWICZ

\subsubsection{Direction of Visitor Movement}

The principal influx of visitors is planned from the northeast, where the main entrance will be located. Only pedestrian traffic will be allowed within the archaeological park. The burial mounds open to visitors are located across the whole area of the archaeological site.

\subsubsection{Information Panels and 3 D Visualizations}

Information panels are to be located at the entrances to the archaeological park and alongside each of the tumuli open to visitors. Panels at the entrance will provide information about the history of El-Zuma's burial mounds and the research that has been carried out into them, as well as about the archaeological park's media patrons and investors. Information about the site's inscription on the UNESco World Heritage List will also be posted.

All of the tombs accessible to visitors, and several other selected tumuli, will have panels with descriptions, drawings, cross-sections, and plans of the burial shafts and their visualizations.

All information on the panels will be provided in two languages: English and Arabic.

\subsubsection{Visiting the Burial Chambers}

The burial chambers in some of the tumuli at the archaeological park will be made accessible to visitors. Because these graves are below ground level, appropriate stair constructions leading to the bottom of the shafts will be needed, as well as some form of closed cover to protect the tombs from weather conditions and damage.
In order to provide visitors with appropriate information based on archaeological research, the burial chambers are to be reconstructed with their human skeletons and furnishings, as found by archaeologists. The grave equipment accompanying the deceased will be put on display, and will include items such as the funeral bed, pottery, baskets, weapons, and everyday objects deposited as votive offerings. These burial goods would be faithful copies of the original artefacts, which will be held in the on-site museum.

In order to create the appropriate visual effect, the burial chamber and the shaft leading to it should be properly lit. Due to the nature of their construction, illumination is of great importance for the presentation of tunnels in type I tombs (large burial mounds). For safety reasons, visitors will only be able to view the tunnels from shaft level [Fig. 9.11].

\subsubsection{Museum Exhibition and Conference and Administration Complex}

It is planned to build a conference and administration compound as well as a museum in the south-eastern part of the archaeological park. The museum will host a traditional exhibition with multimedia elements. 
2.2 Al Takamul Al Handasi Engineering Consultants

Project

The concept described above is based on the general guidelines delivered by UNESCO and ICOMOS. As an alternative, the project of Dr. Abdalla M. Sabbar from Al Takamul Al Handasi Engineering Consultants is presented below [Figs. 9.12-9.14]. 

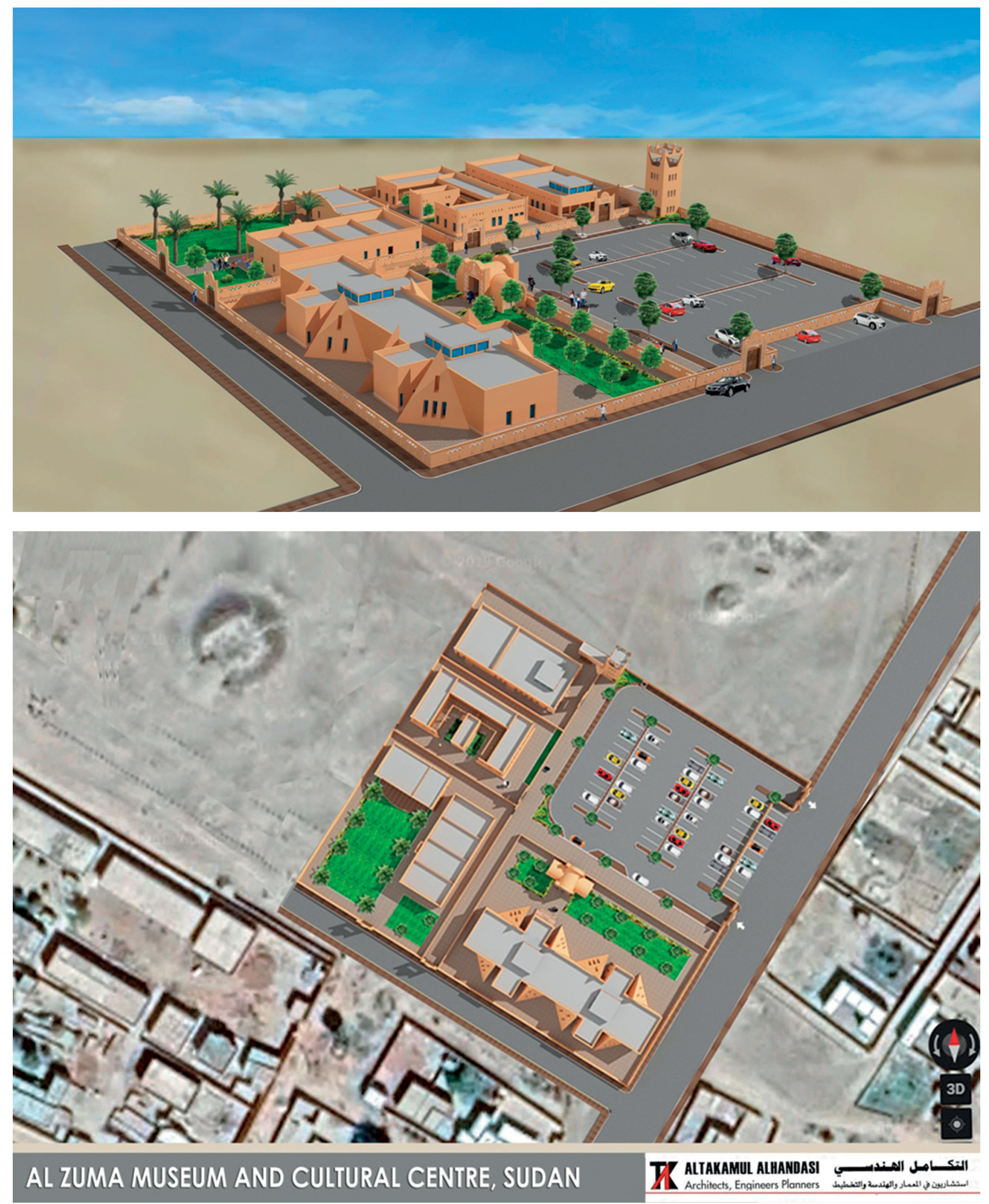

FIGURE 9.12 Computer visualization of the Al Takamul Al Handasi Engineering Consultants' design for the archaeological park

ABDALLA M. SABBAR FROM AL TAKAMUL AL HANDASI ENGINEERING CONSULTANTS 


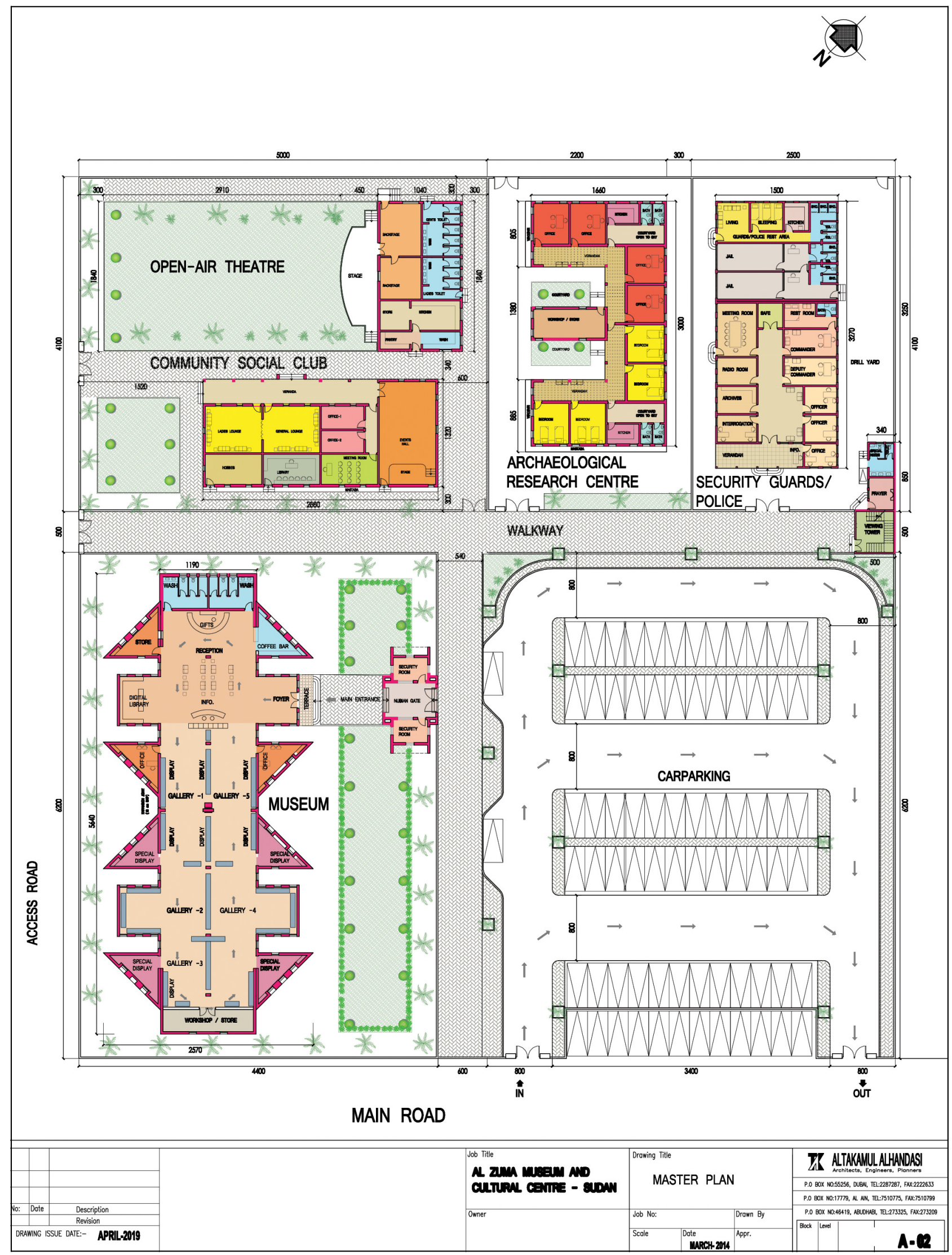

FIGURE 9.13 Plans of the Al Takamul Al Handasi Engineering Consultants' design for the archaeological park

ABDALLA M. SABBAR FROM AL TAKAMUL AL HANDASI ENGINEERING CONSULTANTS 


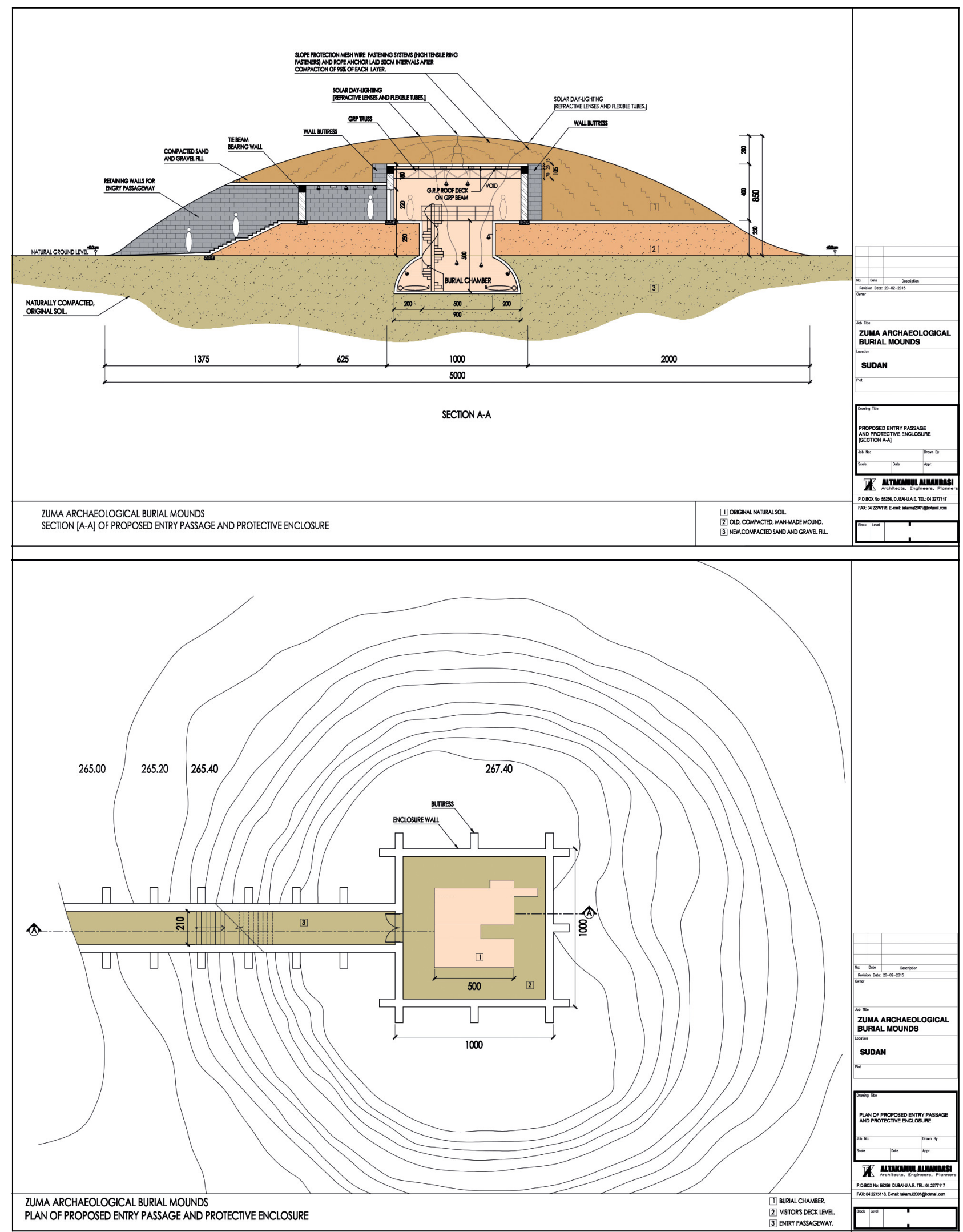

FIGURE 9.14 Hypothetical reconstruction of the tumulus

ABDALLA M. SABBAR FROM AL TAKAMUL AL HANDASI ENGINEERING CONSULTANTS 